\title{
Toward a multilevel perspective on digital servitization
}

\author{
Bieke Struyf \\ Antwerp Management School, University of Antwerp, Antwerp, Belgium \\ Serena Galvani \\ Department of Economics, Society and Politics, University of Urbino Carlo Bo, \\ Urbino, Italy \\ Paul Matthyssens \\ DESM, University of Milano-Bicocca, Milan, Italy and \\ University of Antwerp, Antwerp, Belgium, and \\ Roberta Bocconcelli \\ Department of Economics, Society and Politics, University of Urbino Carlo Bo, \\ Urbino, Italy
}

\begin{abstract}
Purpose - The purpose of this paper is to provide a theoretical lens on digital servitization (DS) for future research purposes. By developing a multilevel framework that helps structure and untangle its complexity, the authors aim to increase understanding into the persistent challenge of DS.

Design/methodology/approach - Building on a problematization approach, critical incident technique was applied to a comparative, longitudinal, multiple-case study in which DS journeys from one Italian and one Belgian manufacturing firm were analyzed.

Findings - Analysis revealed that different levels and elements of the multilevel framework were simultaneously involved in the identified critical incidents. This huge interconnectedness severely challenged the DS journeys. Managerial (un)responsiveness played a central role in the organizational outcome for both firms.

Originality/value - The authors answer the call for a more holistic approach toward DS. A multilevel framework is provided to be employed by future researchers and practitioners alike. A mid-range theory for DS and propositions for future research are developed.
\end{abstract}

Keywords Manufacturing, Industry 4.0, Digital transformation, Digital servitization, Multilevel theory

Paper type Research paper

\section{Introduction}

Since the late 1980s, companies have been described as increasingly offering fuller market packages or "bundles" of customer-focused combinations of goods, services, support, self-service and knowledge (Vandermerwe and Rada, 1988, p. 314). Even at present, services' promise of enabling growth and sustainable competitive advantage continues to motivate manufacturers to bank on such strategies (Vendrell-Herrero et al., 2017; Kowalkowski et al.,2017). Servitization, or the addition of services to manufacturers' core product offerings to create additional customer value (Raddats et al., 2019a, p. 207), has inspired ample research leading to the establishment of a brand new, well-studied field of knowledge in which the

(C) Bieke Struyf, Serena Galvani, Paul Matthyssens and Roberta Bocconcelli. Published by Emerald Publishing Limited. This article is published under the Creative Commons Attribution (CC BY 4.0) licence. Anyone may reproduce, distribute, translate and create derivative works of this article (for both commercial and non-commercial purposes), subject to full attribution to the original publication and authors. The full terms of this licence may be seen at http://creativecommons.org/licences/by/4.0/ legalcode

Multilevel perspective on digital servitization

Received 27 August 2020 Revised 3 December 2020 20 March 2021 30 March 2021 Accepted 31 March 2021 
identification of obstacles to servitization has become a popular topic (Gebauer et al., 2005; Matthyssens and Vandenbempt, 2008; Alghisi and Saccani, 2015).

Despite extensive research, however, companies continue to struggle in their attempt to realize service strategies (Kohtamäki et al., 2020; Zhang and Banerji, 2017). Digitization nowadays adds to this challenge as companies, encouraged by promises of data-driven optimization and innovation, explore how they can provide customers with technologyenabled knowledge-based services (Coreynen et al., 2017). Barriers to the implementation of this strategy known as digital servitization (DS) have been pinpointed (Gebauer et al., 2020b). For example, horizontal and end-to-end integration of systems requires companies to find ways to differentiate themselves from network partners while fostering co-creating relationships with them at the same time (Kamalaldin et al., 2020; Vendrell-Herrero et al., 2017). At a lower level, tensions rise as organizational members try to make sense of the transition from the traditional ways of working toward becoming digital service providers (Tronvoll et al., 2020). Marked as most significant are the organizational hurdles (Bustinza et al., 2018). Particularly unintended consequences of the strategic implementation process often hinder the realization of the expected financial returns (Kohtamäki et al., 2020; Gebauer et al., 2020b). Unfortunately, like with servitization, identifying barriers to DS and solutions to overcoming them seems insufficient to guarantee a smooth evolution. Gaining understanding in this perpetual challenge of effectively transitioning toward digital service strategies is relevant, especially given the COVID-19 crisis (Rapaccini et al., 2020).

In this paper, we therefore aim to unravel the mystery behind the persistence of the DS challenge. Rather than investigating additional barriers, we take a problematization approach and challenge existing theory using critical incident technique (CIT) (Alvesson and Sandberg, 2013; Bott and Tourish, 2016). We question the often-implicit assumption of servitization barriers being independent, clearly discernible and definable issues to which explicit, definite answers exist and ask ourselves: Why do companies continuously struggle with DS despite extensive knowledge on hurdles and approaches to overcome them? A comparative case study on DS in which managers' responses to DS barriers are explored is used as motivation for the development of a multilevel framework in which key ingredients to DS are congregated.

Several theoretical contributions are made. First, calls for multilevel research on servitization (Rabetino et al., 2017; Lenka, 2018) and the development of mid-range theories, which provide insight into potential barriers of organizational change in servitization journeys (Rabetino et al., 2018), are answered. Second, the developed framework meets the demand for frameworks that support decision-making and a more systemic and holistic approach to DS (Paschou et al., 2020). Third, by including microfoundations of DS, we add to the emerging consciousness of the importance of emotions for strategic change and management theories (Ashkanasy et al., 2017). Additionally, practitioners can employ the multilevel framework to support them in taking a holistic and proactive approach toward their DS.

The paper is structured as follows. In the first section, DS's context and content are reviewed based on literature. We present multilevel theory as a novel lens through which to explore DS and introduce our preliminary multilevel framework. Next, we elaborate on CIT, our chosen method for theory building, and introduce our comparative case study. Findings are deducted after which propositions for future research are developed in the discussion section. We conclude with a summary of our results highlighting limitations and future research avenues.

\section{Theoretical background}

\subsection{Digital servitization}

DS, the market strategy that merges servitization with digitization, is a relatively new topic for academics and practitioners (Coreynen et al., 2017; Vendrell-Herrero et al., 2017). 
Research on servitization (Vandermerwe and Rada, 1988), its first essential building block, has been firmly consolidated. Yet, this transformational process of shifting from a productcentric business model and logic to a service-centric approach remains challenging (Kowalkowski et al., 2017, p. 7; Kohtamäki et al., 2020; Zhang and Banerji, 2017). The adoption and exploitation of new digital technologies, DS's second building block, now further complicate this process as digital technologies highly impact the implementation and offering of advanced services and can directly affect customers' core business processes (Coreynen et al., 2017; Vendrell-Herrero et al., 2017).

Paschou et al. (2020, p. 284) comprehensively defined DS as the development of new services and/or the improvement of existing ones through the use of digital technologies [...] to enable new (digital) business models, to find novel ways of (co)creating value, as well as to generate knowledge from data, improve the firm's operational and environmental performance and gain a competitive advantage. Table 1 summarizes recent literature on DS.

Two sections can be distinguished within the different literature streams. The first largely focuses on internal, company-specific challenges. The second mainly investigates external challenges relating to changing stakeholder relationships and network configurations. The employment of divergent theoretical lenses has led to DS authors pinpointing numerous barriers relating to different levels of analysis. Together they reveal an increasing complexity, defined by the number of different items or elements that must be dealt with simultaneously by the organization (Scott, 1992, p. 230), in both the content and context of DS. Several authors have highlighted the need for a more systemic and holistic approach to DS (Paschou et al., 2020) to boost understanding of its challenges. We believe a multilevel perspective can be valuable to structure and unravel DS complexity, which might underlie the perpetual DS challenge. In the next section, we further motivate our choice for and elaborate on a multilevel perspective for DS.

\subsection{A multilevel theory for $D S$}

2.2.1 A multilevel approach as theoretical lens. Given that strategies are always embedded in a multilevel context (industry, market, organization, division, teams, individual) (Matthyssens and Vandenbempt, 2003, p. 598), considering the context in which a DS strategy is developed and implemented can substantially add to the understanding of its success and/or failure (Pettigrew, 1992). Indeed, several authors have pointed out the need for a multilevel approach toward DS (Rabetino et al., 2017; Lenka, 2018).

According to Klein et al. (1999, p. 243), multilevel theory results in a deeper, richer portrait of organizational life in which the influence of the organizational context (macro) on individuals' actions and perceptions (micro) and vice versa is acknowledged. Adopting a multilevel perspective entails taking a holistic approach to interdependencies between actors, resources and mechanisms, which are studied at different levels of analysis. Gaining understanding of these levels and the interactions between them requires and enriches multidisciplinary knowledge (Partington, 2000; Hitt et al., 2007).

Attention is required, however, to how multilevel theories are built, and insights are measured. Collective constructs such as strategy or organizational culture cannot be measured through mere addition of individual perceptions (Molina-Azorín et al., 2020). Neither can constructs from one level of analysis simply be copied to or compared with another level (Paruchuri et al., 2018). Developing multilevel theory holds potential for the realization of synergies through the synthesis of different organizational sciences (Klein et al., 1999). Yet caution is advised upon merging knowledge and concepts from different streams of literature.

Partington (2000, p. 91) stated that multidisciplinary knowledge can be built through iterations between academics and managers who attempt to learn from one another in a virtuous cycle of understanding, explication and action. Qualitative research, through which 


\section{IJOPM}

\begin{tabular}{|c|c|c|c|c|c|c|}
\hline Thematic focus & Mai & n contributions & & oretical lenses & Ref & erences \\
\hline $\begin{array}{l}\text { Firm performance } \\
\text { and strategic } \\
\text { development }\end{array}$ & (1) & $\begin{array}{l}\text { Identification of challenges and } \\
\text { impact of DS on firm performance } \\
\text { DS can have a positive correlation } \\
\text { with firm performance though this } \\
\text { is not guaranteed. The following } \\
\text { elements can have a positive } \\
\text { impact on firm performance: data } \\
\text { analytics supporting the business } \\
\text { model evolution, a proper } \\
\text { relational governance strategy, a } \\
\text { focused sales model and a } \\
\text { sufficient digitization level, which } \\
\text { contributes to the success of the } \\
\text { strategy but also increases its } \\
\text { complexity }\end{array}$ & (1) & $\begin{array}{l}\text { Business Model } \\
\text { Innovation } \\
\text { Organizational } \\
\text { Theory } \\
\text { Strategic } \\
\text { Management } \\
\text { Value Chains }\end{array}$ & $\begin{array}{l}\text { (1) } \\
\text { (2) } \\
\text { (3) } \\
\text { (4) } \\
\text { (5) }\end{array}$ & $\begin{array}{l}\text { Gebauer } \text { et al. } \\
(2020 \mathrm{a}) \\
\text { Kohtamäki } \text { et al. } \\
(2019) \\
\text { Kohtamäki } \text { et al. } \\
\text { (2020) } \\
\text { Paiola and } \\
\text { Gebauer (2020) } \\
\text { Parida et al. } \\
\text { (2019) }\end{array}$ \\
\hline $\begin{array}{l}\text { Organizational } \\
\text { development }\end{array}$ & (1) & $\begin{array}{l}\text { Investigation of organizational } \\
\text { resources reconfiguration in } \\
\text { support of DS complexity and the } \\
\text { implementation of novel business } \\
\text { models } \\
\text { A competitive DS strategy relies } \\
\text { on crucial capabilities: strong firm } \\
\text { commitment, strategic agility, } \\
\text { deployment of digitization and its } \\
\text { fusion with service }\end{array}$ & $\begin{array}{l}(2) \\
(3)\end{array}$ & $\begin{array}{l}\text { Dynamic } \\
\text { Capabilities } \\
\text { RBV } \\
\text { Value Co-creation }\end{array}$ & $\begin{array}{l}\text { (1) } \\
(2) \\
(3) \\
(4) \\
(5)\end{array}$ & $\begin{array}{l}\text { Bustinza et al. } \\
\text { (2018) } \\
\text { Coreynen } \text { et al. } \\
(2017) \\
\text { Frank et al. } \\
\text { (2019) } \\
\text { Hasselblatt et al. } \\
\text { (2018) } \\
\text { Saunila et al. } \\
\text { (2019) }\end{array}$ \\
\hline
\end{tabular}

Supplier-customer relationships
Table 1.

DS literature review table - thematic focuses and theoretical lenses implementation, digital

management capabilities and skills facilitating integration into customers' processes and the development of high-value services

(1) Exploration of resources, strategies or relational approaches, which can support and optimize changing suppliercustomer relationships

(2) Supplier-customer relationships are fundamental to DSTs and require among others a suppliers' ability to deploy unique resources to maintain its strategic position in the supply chain, a firm's ability to develop supplier-customer relational intimacy and informational openness and co-create with customers from the early stages of DST in an agile, iterative approach and customers readiness for advanced services, something manufacturers should promote
(1) SCM
(2) Industrial
Marketing
(3) Business Relationships
(1) Grandinetti et al. (2020)
(2) Kamalaldin et al. (2020)
(3) Sjödin et al. (2020)
(4) Vaittinen and Martinsuo (2019)
(5) Vendrell- Herrero et al. (2017) 


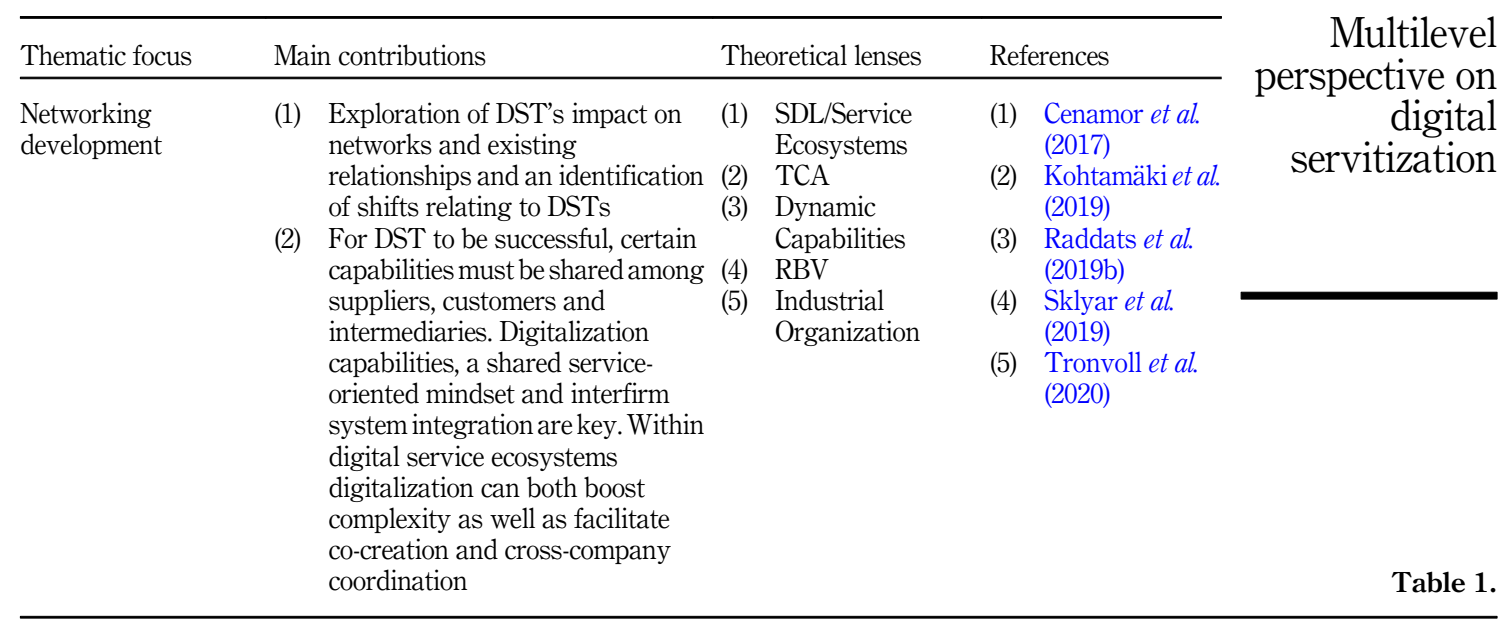

fine-grained data is collected, can contribute to this learning process by uncovering new elements, which underwrite the success and/or failure of novel phenomena (Eisenhardt, 1989). Hence, this paper was developed in an abductive way in which literature and case study insights were integrated through systemic combination (Dubois and Gadde, 2002). In the next section, the preliminary multilevel framework from which the iterations started is presented.

2.2.2 Introducing the multilevel framework for DS. A three-tier analytical framework (Table 2) was developed based on literature on determinants of DS. The framework provides a multidisciplinary perspective (Partington, 2000) and brings together insights from, among others, ecosystem theory (network level), strategic management and organizational behavior (organizational level) and psychology and behavioral sciences (microfoundational level).

2.2.2.1 Microfoundational level. A microlevel perspective was incorporated following the call of Rabetino et al. (2017, p. 155) for the inclusion of psychological and sociological insights to increase understanding of servitization pathways based on individual perceptions, behaviors and interactions among individuals. Within this level, microfoundations of organizational decision-making, routines and (dynamic) capabilities are comprised (Helfat and Peteraf, 2015; Hodgkinson and Healey, 2014) with the goal of understanding how actors, their interactions and the mechanisms and context that influence such interactions, produce firm-level and collective heterogeneity (Felin et al., 2015, p. 605).

Microlevel mechanisms consist of intertwined cognitive and affective processes, which mediate organizational practices (Hodgkinson and Healey, 2014). They can be discerned at the individual level, between individuals of the organization or even at the unconscious level where basic cognitive processes are studied (Waldman et al., 2019). Emotion contagion, for example, is an affective process in which emotions spread from one individual to the next, leading to the emergence of a group level mood or collective emotion (Barsade, 2002). Studies show that collective emotions can significantly influence managerial perception of the need for change, strategic decision-making and change outcomes (Vuori and Huy, 2016; Healey and Hodgkinson, 2017). Taking this level into account is therefore essential to understanding DS journeys.

According to Gioia and Chittipeddi (1991), a manager's main role in initiating strategic change consists of sensemaking and sense giving. This entails the reconceptualization of the organization to fit the strategic change (sensemaking) followed by the dissemination of this 


\begin{tabular}{lll}
\hline Level Component & References \\
\hline
\end{tabular}

Network level, e.g. value partners, clients, suppliers, intermediaries

Organizational level, e.g. firm-wide processes and mechanisms

Microfoundational level, e.g. mechanisms, which affect managerial and team sensemaking and mobilization
Table 2.

Preliminary multilevel framework on DST
(1) Network and supply chain position

(2) Division of power and competition

(3) Trust throughout the network and interfirm dominant logic

(4) Interfirm system integration, digital maturity and readiness

(5) Co-creation and interactively developed capabilities

(6) Service platforms, ecosystems and governance

(1) Strategy and business model development

(2) Resource configurations, (dynamic) capabilities and resources

(3) Organizational identity, structure and culture

(4) Continuous internal and external alignment led by management

Microfoundations of organizational decision-making, routines and (dynamic) capabilities, among which

(1) Cognitive processes, such as managerial perception, cognition, sensemaking and sense giving

(2) Affective processes causing collective and individual emotions such as emotion contagion
Helfat and Raubitschek (2018), Kohtamäki et al. (2019), Matthyssens and Vandenbempt (2008), Raddats et al. (2017),

Sklyar et al. (2019), VendrellHerrero et al. (2017)

Alghisi and Saccani (2015), Bustinza et al. (2018), Coreynen et al. (2017), Kohtamäki et al. (2020a), Tronvoll et al. (2020)

Felin et al. (2015), Helfat and Peteraf (2015), Hodgkinson and Healey (2014), Lenka et al. (2018a), Rabetino et al. (2017)

new company vision among stakeholders (sense giving). By effectively framing change initiatives in a way that connects with and reshapes the shared idea of what the organization stands for, managers can mobilize employees to align their actions and thoughts with the new organizational reality (Raffaelli et al., 2019). Helfat and Peteraf (2015) also highlighted managerial cognition as a microfoundation of an organization's ability to sense, seize and reconfigure the organization's resources to fit the desired and/or required strategic change. Especially in radical innovation efforts, emotion too plays an important role in engaging key players. With the power to evoke strong commitment to novel choices, it is essential to the adaptive capacity of individuals and organizations (Hodgkinson and Healey, 2014, p. 1310).

Since both servitization and digitization are described as disruptive and requiring radical organizational change (Vendrell-Herrero et al., 2017), DS journeys are likely to challenge the "cognitive maps [1]" of managers (Helfat and Peteraf, 2015) and evoke strong emotions (Vuori and Huy, 2016). To date, however, microlevel perspectives on DS remain scant. Lenka et al. (2018a) showed how microfoundations can facilitate servitization transition by countering organizational resistance. Coreynen et al. (2020) found that differences in decision-makers' motivations - whether they were driven by the need for achievement, affiliation or power - 
influenced organization's chances at pursuing servitization. Both studies offer a starting point for investigating how microlevel mechanisms can smoothen or interfere with DS pathways.

2.2.2.2 Organizational level. Since DS involves a change in business strategy, which is central to aligning the internal and market environment (Alghisi and Saccani, 2015), its implementation requires a revision of the entire organizational constitution (Vendrell-Herrero et al., 2017; Bustinza et al., 2018).

First, resource configurations must be rearranged to fit the digital strategy and business model (Coreynen et al., 2017; Parida et al., 2019). New capabilities are necessary to benefit from technological opportunities. Existing product-related knowledge is essential yet insufficient for DS success (Paiola and Gebauer, 2020). Digital service capabilities, which facilitate knowledge absorption from customers and enhance an organization's ability to co-create value, are vital (Saunila et al., 2019). Hasselblatt et al. (2018) further listed digital business model development, the building of scalable solution platforms, IoT value selling and delivery, business intelligence and measurements as key capabilities for DS. Additionally, organization-wide commitment and a better operational product-service configuration are required to making DS work. Some critical resources, among which strategic ability, might be acquired externally (Bustinza et al., 2018).

Next, the organizational structure and its underlying processes must be reconfigured to support the digital service provision. According to Bustinza et al. (2018, p. 112), DS requires an organizational structure with the capacity to constantly reconfigure the firm's strategic capabilities to meet continuously evolving customer needs. Shifting from centralized to decentralized operations and from physical products to dematerialized data not only challenges organizational structure (Tronvoll et al., 2020). Role conflicts might emerge causing internal tensions. Organizational dissonance is expected to be fed by the ambiguity following the simultaneous focus on products and services and the accompanying conflicting behavioral and attitudinal expectations (Lenka et al., 2018b, p. 813). Establishing a strong service-oriented organizational identity and culture, which endorse a synergetic relationship between manufacturing and service orientation, can help in managing this ambiguity and consolidating DS-oriented organizational change (Tronvoll et al., 2020).

Finally, flexibility and continuous internal and external alignment are key to realizing the necessary changes (Bustinza et al., 2018). Misalignment between investments in digitization and the level of servitization could be detrimental to financial performance (Kohtamäki et al., 2020). Literature has indicated that leadership and managerial commitment play a central role in aligning for DS (Yeow et al., 2018; Bustinza et al., 2018). Additionally, the presence of transparency, customer involvement, constructive relationships with partners and extra personnel can facilitate the DS journey (Hämäläinen, 2020).

2.2.2.3 Network level. Since collaborations with external actors are required to effectively realize advanced digital solutions, an examination of the DS context seems crucial (Pettigrew, 1992; Sklyar et al., 2019). Indeed, existing relationships and network dynamics are expected to be impacted by DS (Kamalaldin et al., 2020; Kohtamäki et al., 2019). Given that network and supply chain positions might change, firms are encouraged to actively explore new relationship equilibria (Adner, 2017) and exploit their difficult to imitate factors to preserve their relational power and competitiveness (Vendrell-Herrero et al., 2017). Trust between value partners is key (Gebauer et al., 2020a). Though traditionally not prevalent in the manufacturing industry (Matthyssens and Vandenbempt, 2008), trust has been shown to be essential to and follow from DS implementation. After all, digitization facilitates openness and operational transparency, which both underwrites and necessitates a novel shared interfirm dominant logic (Tronvoll et al., 2020).

Digitization also supports interfirm system integration, which further enables crosscompany collaboration (Sklyar et al., 2019). To participate in and benefit from horizontal 
integration, however, digital maturity must be sufficiently high (Frank et al., 2019). Customers should portray digital readiness in terms of IT systems, mindset and capabilities (Vaittinen and Martinsuo, 2019). In fact, specific capabilities should be acquired by all network actors to stimulate collaboration and innovation (Raddats et al., 2019b). Understanding partner needs is important as DS requires intensive collaboration between provider and customer (Kamalaldin et al., 2020, p. 2). Furthermore, co-creation practices in which complementary capabilities are exchanged can generate interactively developed capabilities enhancing, among others, knowledge and service development (Raddats et al., 2017). Finally, being able to access customers and data (Grandinetti et al., 2020) and actively involve clients in the co-creation process (Saunila et al., 2019; Sjödin et al., 2020) is essential too.

Digital platforms, technological infrastructures that allow firms to develop, configure and deliver advanced services efficiently (Cenamor et al., 2017, p. 55) exemplify high interfirm system integration. Several parties can be involved, among which are suppliers, complementors and customers. For platforms to result in positive cross-side network effects, a governance structure must be designed specifying incentives for and rules on participation and interaction (Helfat and Raubitschek, 2018). This is in contrast to traditional service ecosystems, which are known as "relatively" self-contained, self-adjusting system [s] of resource-integrating actors connected by shared institutional logics and mutual value creation through service exchange (Lusch and Vargo, 2014, p. 161).

The relational nature of ecosystems, which bring together unfamiliar actors with diverging interests, makes it impossible to analyze DS in isolation (Kohtamäki et al., 2019). Studies show that applying a multi-actor perspective might help in gaining deeper insight into challenges relating to the realization of advanced services (Kamalaldin et al., 2020; Story et al., 2017).

2.2.2.4 Cross-level interconnectedness. Additionally, literature hints toward the existence of cross-level interconnectedness. For example, organizational actions, such as trainings aimed at boosting servitization related knowledge, might influence motivations of decision-makers at the microfoundational level, which in turn may enhance the chances of organizations pursuing DS (Coreynen et al., 2020). At the same time, strategic involvement of customers and partners is required at the network level to effectively design servitization business models and implement the strategy at the organizational level (Bustinza et al., 2018; Kohtamäki et al., 2019). However, to benefit from network partner involvement, organizations need to recalibrate their competences and mindset in the first place (Kamalaldin et al., 2020; Tronvoll et al., 2020). Actions and decisions on one level hence seem to influence the effectiveness of other levels simultaneously. Despite many studies suggesting such interdependencies, the phenomenon of cross-level interconnectedness has not yet been investigated in-depth.

\section{Methodology}

3.1 Method

CIT (Flanagan, 1954) was chosen as a central method based on the exploratory nature of our research question and our desire to challenge existing theory (Bott and Tourish, 2016). The qualitative method focuses on critical incidents in which people's behavioral response to practical challenges encountered in a specific situation and the perceived consequences of these behaviors are studied. Critical incidents are described as major events or a series of interlinked events that characterize the start of a next stage in a development process. They can be negative in nature resulting in an undesirable outcome, or positive, as characterized by an opportunity or potentially causing a positive outcome (Durand, 2016). Semistructured interviews are used to collect the behavioral data. By applying an open-ended approach in which data is gathered free from references to pre-existing theories, rich descriptions of key incidents are generated, which offer a greater opportunity to shed new light on old phenomena 
and thus to challenge long-established theoretical accounts (Bott and Tourish, 2016, p. 277). Former research has proven CIT's value for providing deeper understanding of the intricacies and contextual factors surrounding behaviors (Bott and Tourish, 2016, p. 278) and for increasing understanding into and revealing "hidden" aspects of disruptive transitions (Durand, 2016, p. 87).

In this work, CIT was applied to two cases on which a comparative, longitudinal, multiplecase study was built (Eisenhardt, 1989; Yin, 2011). The reason for this is threefold. First, case studies have proven beneficial for theory development in dynamic contexts (Pratt, 2009; Matthyssens and Vandenbempt, 2003). Second, by purposefully selecting (Patton, 2005) two similar cases that are set in different geographical contexts, one in Italy and one in Belgium, their comparison may lead to the identification of differences in implementation logic and approach that could contribute to our understanding of what facilitates or hinders DS journeys. Furthermore, the longitudinal nature of the research supports increased understanding of process dynamics, a causal perspective on behavior and comprehension of the evolution of the DS over time (Quintens and Matthyssens, 2010). Since it is our goal to gain clarity on what continues to challenge managers in their journey toward advanced DS, a longitudinal comparative case study seemed valuable.

Important to point out is that the case study is used as motivation for the developed multilevel framework rather than it being the focus of our paper (Siggelkow, 2007). It is not our intention to identify implications, which can be generalized further. The case is used in iteration with the literature through systemic combining for theory development (Dubois and Gadde, 2002).

\subsection{Data collection and analysis}

Both the Italian and Belgian cases followed their company throughout the years in which the DS initiative took place. In the Mectop [2] case (IT), information was collected over a 4.5-year period. For Apitec [2](BE), data was gathered over ten years. Semistructured interviews with diverse key actors were conducted with the aim of gaining insight into critical incidents (Table 3). Individuals at the organizational and network level were questioned on managerial responses to DS barriers and the consequences of their behavioral choices for the consecutive DS journey. Interviewees were purposefully sampled based on their involvement with the DS initiative and/or their unique perspective on its evolution (Patton, 2005). A snowballing technique was applied in which respondents were asked "Who else might have a unique

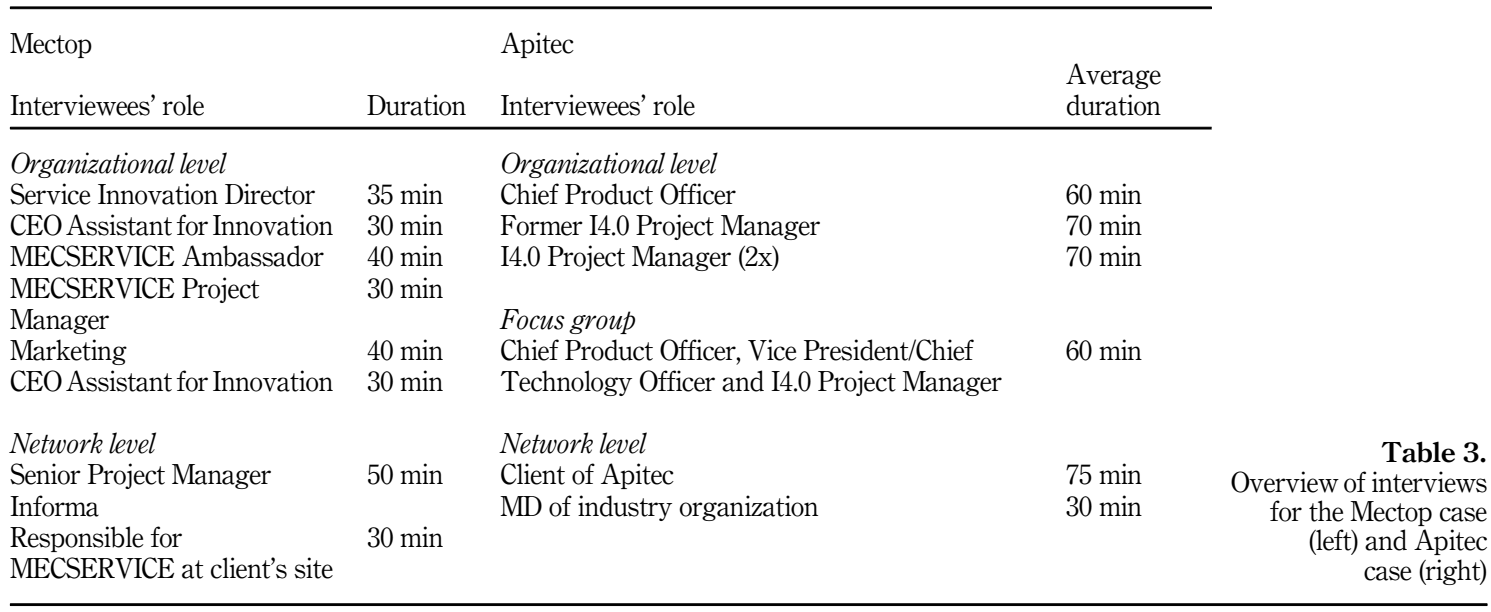


perspective on the evolution of the DS?". Interviews were undertaken until saturation was reached (Bott and Tourish, 2016).

By gathering diverse viewpoints on the critical incidents, we were able to add nuance to our dataset and counter bias (Silverman, 2008). This allowed for the discovery of novel critical incidents where certain respondents had trouble recalling instances or felt reluctant to share sensitive information, common challenges to CIT. To motivate revelation of critical incidents, respondents were guaranteed full anonymization of the case. Additionally, generic probes such as "Who else was involved? What were the challenges? What was the impact?" were used to encourage dialogue while avoiding data contamination through leading questioning (Bott and Tourish, 2016).

Congruent with CIT, content analysis was used to examine the data. In a first step, critical incidents were discerned through conversations with key stakeholders and discussions between researchers. Next, a combination of data-driven and theory-driven coding took place, consistent with our abductive approach (Dubois and Gadde, 2002). Major incidents were scrutinized using the components outlined in the preliminary multilevel DS framework while we remained open to alternative interpretations of the empirical data. Engaging our empirical data in a critical dialogue with theory supported our goal of challenging existing theory (Alvesson and Sandberg, 2013).

Comparing critical incidents between cases enabled us to distinguish overarching patterns in their development. Four major events were acknowledged as pivotal to the DS evolutions. In the following section they are introduced for each case.

\section{Case descriptions}

\subsection{Italy-based Mectop: from manufacturing excellence to smart service provision}

Italian B2B company Mectop originated in the 1970s. The company specializes in producing industrial machineries for the manipulation of natural and advanced materials. After having known considerable growth, the family business nowadays operates worldwide in 39 legal entities and 12 manufacturing sites, offering employment to nearly 4,400 employees.

In 2017, Mectop invested in an IoT-based DS project, named MECSERVICE. With this new brand and platform, the firm provides and delivers digital and traditional services. Machineries are equipped with sensors that monitor their activities and technical needs. Based on these data, MECSERVICE offers clients services such as preventive maintenance and error notifications, video remote assistance and key performance indicator (KPI) measurements. The five-year project was realized in collaboration with international consultancy agency, Informa. In the year of MECSERVICE's launch, the Italian government presented the National Industry 4.0 Plan. The plan that intended to proactively support technological innovation of Italian firms included interventions among which financial contributions, credit access and tax relief. It turned out to be a crucial factor in digital solution investments made by Mectop's customers.

Incident 1: In 2016, Mectop became aware of rising technological opportunities. Its management understood that, to gain significant competitive advantage, they would need to seize the opportunities before everyone else did. In Europe, many manufacturing companies were looking for ways to recover from the economic crisis (2008-2011). The entire market experienced a need for innovation. The firm's innovation department traveled to Germany to learn from the country's main competitors in which direction Industry 4.0 was heading. The journey resulted in an innovation push toward first mover advantages and a shared perception of the need for change.

Simultaneously, the company's relationship with Informa was reinforced. Previous collaborations between the firms had been positive. Informa had gained experience in DS projects in, among others, the automotive industry and suggested Mectop to invest in DS. 
Incident 2: After the board of directors decided to adopt DS in 2017, the firm's business model was radically changed to fit this new strategy. Monetizing digital services was new to Mectop, which had previously only provided customers supporting services free of charge. MECSERVICE was to guarantee a stable income complementary to the fluctuating sales of its long-life machines. The platform embodied a Product-Service System (PSS), a system in which the company's product offering was enhanced by a series of services, which were strictly related to the sold products. Clients could use the platform to buy spare parts in the online store and to consult technical documents. Proactive services could be provided to prevent machines from failing. The project was kicked off by a pilot session in which customers were invited to test MECSERVICE. After positive results the official launch followed. A webpage devoted to MECSERVICE was introduced.

Initially, the project caused internal frictions. Departmental silo thinking led to resistance among managers who perceived MECSERVICE as an addition to their regular workload. Their opposition hindered cross-functional collaboration, which produced a significant barrier to the DS. Different departments needed to be mobilized to realize the project, among which are IT, Services, Innovation, R\&D and Marketing. Aligning them and fulfilling requirements in terms of human resources, competences and capabilities was a first challenge. Alleviation was found in the recruitment of new resources. The Service Innovation Director, responsible for leading MECSERVICE-staffed employees, was hired. Younger employees and technicians of the MECSERVICE project were particularly motivated. Working directly for the Service Innovation Director offered them clear visibility at top management level, which was perceived a huge benefit for their future career.

Incident 3: Faltering performances between the end of 2017 and the start of 2019 urged management to revise the initiative. This phase had been reserved for market rollout, internationalization and adaptation of all machine models involved in the provision of digital services. Notwithstanding, deadlines and KPIs were not met. The project decelerated. Immediate improvements were required. Difficulties were encountered at different levels. First, not everyone inside the firm was committed to nor positive about the project. The strongly embedded product-based logic held back employees from transitioning toward a service-oriented mindset. Second, clients seemed to not fully perceive the value of MECSERVICE, nor understand its potential benefits. Third, Mectop struggled to effectively make use of big data collected through MECSERVICE. The overwhelming amount made it hard to extract value from it.

Mectop responded with actions at both the organizational and network levels. Internally, training sessions were organized among employees to increase diffusion of capabilities and knowledge. A marketing campaign was dedicated to raising employee awareness of MECSERVICE and the benefits it brought. One of the actions entailed providing employees access to a dedicated project page on Mectop's intranet. Concurrently, the marketing department embarked on a mission to reconnect with the market. Training sessions were organized for customers to enhance their knowledge about MECSERVICE's functionalities. The strong, positive relationship with Informa supported Mectop throughout the challenges.

Incident 4: From the end of 2019 on, the firm's strategy was continuously fine-tuned, resulting in Mectop becoming more services-oriented and connected with the market. The board of directors had realized that a strategy revision was necessary to meet customers' needs and exploit the firm's key capabilities. They extended MECSERVICE from a PSS to a complete services platform, which lent customers unified access to digital and traditional services against payment. A customer segmentation exercise aimed at the clear identification of customers' needs would later facilitate the offering of tailor-made service packages.

Leadership embodied by the Innovation Director, the Service Innovation Director and the Information Technology Director was crucial for continuous improvement. Biweekly, two meetings would be held among them. The first focused on business and organizational- 
related challenges. The second, a technical meeting, was reserved for platform-related and other analytical questions. (Operative) employees could attend the meetings to raise and discuss issues. At times, solutions would be discussed together with employees before final decisions were taken. Informa also attended the business meetings. Its participation lightened the load for managers who no longer perceived the project as stressful.

Managers and employees were strongly motivated to work on MECSERVICES, except for the sales team. Mectop's salespersons who benefited from product sales' commissions remained stuck in their product-oriented mindset. They considered selling machines more profitable and used MECSERVICE mainly to lure clients into buying extra products. In response to their lack of motivation, KPIs were drawn up to enable the rewarding of services sales. In a first meeting, those KPIs and the accompanying new way of evaluating were shared with the sales team. In a consecutive workshop, Mectop invited its salespersons to share their ideas on the improvement of service sales and the digital tools, which might support them in their effort. Additionally, management of the sales and service departments were merged to increase integration and alignment between both DS essential activities. This merger also confirmed and made visible the announced cultural change toward services.

\subsection{Belgium-based Apitec: from servitization-savant to total digital solution provider}

Recognized for its innovative nature, Apitec designs and produces solutions for the construction industry through installers, who customize the product to the specific installations in which they are integrated. The MNE with a family business character has known tremendous growth over a short period of time leading to its worldwide operations currently. From the very beginning, services were included in the manufacturer's offer. In the 1980s, Apitec started experimenting with programming and machine-to-machine communication. One could say that the company recognized the benefits of services and technology from very early on.

In the early 2010s, the company decided on expanding the digital services offer. The total solution coined AFLUX would consist of a manufacturing executive system supporting clients in the optimization of their own operations. A redesign of their workflow and the installation of a paperless production environment would boost clients' efficiency and competitiveness. In a later stage, a web-based dashboard was added to the application allowing clients to monitor their installation production projects $24 / 7$ from anywhere.

Incident 1: In the late-2000s, one of Apitec clients approached the firm with an idea for a novel digital solution. The automation manager, who would become the project's main champion and Apitec's digitization lead (DL), agreed to explore the opportunity together in co-creation. Meetings with potential software partners were held and market interest was gauged. Inquiries into general interest, willingness to pay and desired features were made. The results were positive. Customer support and interest for the idea grew as the news spread via Apitec's sales representatives.

Simultaneously, the DL employed his/her influence to gain support internally. Unfortunately, management was not ready to invest in the solution. Lack of budget and pre-existing intricacies between the firm's systems and software supplier Ergon's application motivated the continuation of a co-creating partnership between Apitec and Ergon, despite awareness of its suboptimal nature. Ergon held complementary capabilities, yet its developed general application did not entirely fit Apitec's local market requirements of customization and variability. The collaboration did however allow to immediately kick off of the development of the new solution and save costs.

Incident 2: At the beginning of the 2010s, Apitec experienced an innovation push toward first mover advantages. Belgian industry organizations were campaigning strongly for I4.0 implementation and the external buzz in combination with internal presentations held by 
people from the DL's network quickly turned around managers' minds who ended up considering digitization as key to Apitec's future competitive position. Preparations, which until then had mainly taken place under the company's radar, allowed the firm to quickly shift gears. The digital solution was given more visibility and was included into the strategy and budgeting cycle. The official start of the AFLUX project was given.

Incident 3: Around 2013/2014, internal and external tensions started to complicate the DS journey. Clients who had volunteered to test run the application were reporting problems. Pressure on the technical support team increased. A need for extra human resources and organizational structures that could facilitate the mounting feedback emerged. The search for additional team members was cumbersome. The job required a unique combination of technical knowledge, ICT skills, social skills and commercial flair, which seemed hard to find. Furthermore, Ergon, European market leader in its own segment, was following its own course leaving technical issues unresolved, necessitating a ticketing system that supported following up on open issues. Organizational action in response to the situation was delayed.

Management's belief in the solution faltered with the accumulation of technical issues. Their commitment decreased, which further hindered the allocation of resources necessary for remediation. Persisting delay in reinforcements and relief evoked frustration in the technical support team. Eventually, their distress and ensuing indifference started filtering through in conversations with customers. Clients themselves also experienced frustrations. Strong responses to malfunctioning of the application were common. AFLUX infiltrated deeply into clients' core businesses and could endanger their production process. Hence, sales representatives were confronted with dissatisfied customers. The salespersons, who had already shown resistance at the initiation of the project due to unfamiliarity with the technology and low involvement in the development of the application, felt lost when clients' questions were put to them and frustration was laid down at their feet. The continuation of bad news combined with deficient knowledge of ALFUX amplified their initial discomfort. The salespersons' belief in the solution decreased and discouraged them from selling the application.

Incident 4: By the end of the 2010s, the unsolved technical issues resulted in a $50 \%$ success rate of the project. At some clients' sites, the application was working very well. International rollout had commenced. For others, however, AFLUX's troubles continued. One of the clients, a long-term software tester for Apitec, presented the company with a formal notice of default in response to persisting problems on his site. Two years later, no solution had been received. Together with his own programmer, however, the client had continued exploring answers. In less than 12 months, they had succeeded in realizing a solution. Willing to share this knowledge, the client was discouraged by management's response, who seemed to perceive the solution as a threat rather than an opportunity to help Apitec's clients.

Internally, support for the application continued to fall making it increasingly hard for the DL to keep up morale in the support team and to continue working toward answers for clients. A ticketing system had been installed, yet solutions from Ergon remained absent. Continuing shortage of managerial support and proper organizational action eventually led to the DL leaving the organization of which he/she had been part for over 20 years. At the writing of this paper, the future of the application is unsure.

\section{Findings}

Purposeful sampling caused us to select companies with a similar starting point, among which a shared family business background, experience with rapid growth and digitization prior to the start of the DS projects. This common ground might have contributed to the initial stages of the DS journeys being rather alike, with both firms responding quickly to the 
external market push toward I4.0 aiming for a first mover advantage. Misalignment between strategy, market and internal operations, however, ensued. Different responses developed in answer to these multilevel tensions put the companies onto different pathways leading to contrasting project outcomes. A confrontation between our data, critical incident analysis and the multilevel framework resulted in Table 4, which presents dissimilarities between the cases, which span the network, organizational and microfoundational level. We highlight some of the key differences further.

A first distinction was found at the network level. The former positive relationship with co-creating network partner Informa instilled confidence in Mectop regarding its DS competencies and ability to support them through change. This trust-based relationship facilitated the development and realization of Mectop's digital solution at the organizational level. Conversely, Apitec's relationship with Ergon was troubled before AFLUX's development. The supplier held the power. Apitec's inability to effectively manage its supplier and push for timely solutions caused stress at the microfoundational level. Ineffective organizational responses followed, which negatively affected the client relationships at the network level. The DS challenge of co-creation hence involved processes present at network, organizational and microfoundational level. Interdependencies and reciprocity between these processes facilitated Mectop's journey but complicated management of Apitec's DS issue - that is, the realignment of co-created systems to match customer needs - hindering DS progress.

Another difference can be found in the process and content of the implementation of the DS strategy. Mectop's management perceived DS success as congruent with its own future career. This strong commitment toward DS at the microfoundational level spurred on an engaged, top-down approach, which materialized into a well-defined, frequently reevaluated business and action plan. Prompt recognition of misalignment was followed by decisive action, which positively affected organizational mobilization. Contrarily, Apitec took a more bottom-up, trial-and-error approach without a clearly demarcated plan or budget. Misalignments at the organizational level were not as easily perceived by management, which resulted in delayed organizational actions and increased tensions at the microfoundational level. The DS challenge of organizational mobilization was influenced by a complex interplay between, among others, individual motivations of leadership, managerial ability to perceive tensions and develop fitting, timely responses and organizational structures, which facilitated this process.

The critical incidents clearly illustrate continuous interactions between the different levels of the multilevel framework (Table 2). Microlevel processes were abundantly present throughout both DS journeys with affective mechanisms underpinning key decisions, influencing organizational effectiveness and outcomes in a positive or negative way. Misunderstandings and choices made at one level visibly impacted the others.

Management's (un)responsiveness to DS barriers was one of the key differentiators potentially explaining the divergent organizational outcomes. Inaction caused the companies to become trapped in a state of misalignment. The Mectop case showed that appropriate organizational action could move a company forward again. An example can be found in the mobilization of Mectop's sales team. Management noticed the reluctance of the team, which stemmed from unfamiliarity with selling services and misalignment of incentives. They responded with a revision of organizational remuneration structures and trainings aimed at boosting salespeople's ability and willingness to sell digital solutions. The realignment with the new service-dominant logic at organizational level flowed back to the microfoundational level where salespeople felt more inclined to sell services. In addition, Mectop's clear company-wide communicated strategic plan and cross-functional unit dedicated to the execution of I4.0 facilitated organizational mobilization in contrast to Apitec where plans remained vague and the initiative rather local. 


\begin{tabular}{ll}
\hline & Mectop \\
\hline Network level & Network partners, trust and power \\
& Arms-length relationship with customers
\end{tabular}

Previous positive collaborations with consulting firm Informa have established a relationship of trust. Informa suggests strategic DS change to Mectop

\section{Integrated systems}

Low integration between Mectop's, its clients and supplier's system. The developed digital solution does not directly influence client's core processes
Apitec

Close relationships with customers. The AFLUX application idea is presented to Apitec by one of its customers A previously difficult collaboration with software supplier Ergon sets the tone for the co-development of AFLUX

Medium to high integration between Apitec's and its client's operations. High dependency on the software supplier's systems. The digital solution deeply integrates with and affects the core processes of Apitec's clients

Organizational level Strategy development and business model design

Services offered as a new product

Top down implementation of a mostly predefined business and action plan developed and executed in collaboration together with external partner Informa. Clear managerial commitment toward DS all throughout the implementation phase Clearly defined project scope, budget, objectives and measurements
Services offered to increase product sales Bottom-up development of a client requested solution. Trial and error approach. No external partner present to structure the initiative. Management's commitment fluctuates throughout the project

Project scope, budget and objectives are unclear. Few measurements provided for project evaluation

\section{Resource configurations, (dynamic) capabilities and resources}

Little experience with selling services. Basic supporting services are offered for free at the start of the project Digital products have been sold before but this is the first time the digital product is linked to services. Little to no experience co-creating with customers Project champions are situated at top management level

Experience with advanced servitization. Another digital application has already been sold to clients. Some experience with co-creating digital solutions with software partner Ergon and Apitec's clients (testers)

Project champions are situated at middle management level

\section{Organizational identity, structure and culture}

Strong product-dominant logic at the start of the DST. Hierarchical and structured organization
Strong service-dominant logic at the start of the DST. Less hierarchical. Less organizational structures in place to support activities

\section{Continuous realignment and change management}

Clear, decisive organizational action is taken in response to distinguished misalignments. Management takes the lead in developing and implementing solutions
Limited managerial involvement leads to low awareness of misalignment and the urge for action. Organizational responses are delayed. Digitization lead and customers take the lead in looking for solutions
Table 4.

Dissimilarities between Mectop and Apitec's DST: A multilevel 


\begin{tabular}{lll}
\hline & Mectop & \multicolumn{1}{c}{ Apitec } \\
\hline $\begin{array}{l}\text { Microfoundational } \\
\text { Level }\end{array}$ & $\begin{array}{l}\text { Microfoundations of organizational decision-making, routines and (dynamic) } \\
\text { capabilities }\end{array}$
\end{tabular}

Management perceives the success of MECSERVICES as intertwined with their own future (successful) careers. A shared perception of the need for change emerges early on in response to the external market push. Objectives from management and the innovation department are aligned. High commitment is shown throughout the entire project

Employees show initial resistance to the unfamiliar nature of the new serviceoriented strategy. Trainings are organized to raise engagement and understanding of the tool. Together with Informa's support, Mectop succeeds at turning the situation around

Mectop's sales team considers selling services less profitable since it is not rewarded via their commission. The team does not comply with the new DS strategy until additional organizational measures

Table 4.
Management does not seem convinced of AFLUX's value for Apitec's future competitive advantage. Despite an initial mind shift in response to the external market push for innovation, managerial engagement and involvement quickly drop back to low levels of interest. Mobilization of top management and key influencers remains difficult throughout the project

Despite previous positive experience in co-creating a digital solution with clients, high stress levels are experienced by the support team. The increasing amount of unresolved technical issues in combination with delayed organizational action moves the team from initial engagement to frustration to indifference. Eventually, customer contacts start to get affected Conversations with disgruntled clients, affect the sales team's attitude toward AFLUX. Their initial suspiciousness turns into a reluctance to sell the application. Sales of the application come to a halt

The Apitec case demonstrates how bottom-up initiatives without support from top management are likely to experience a more challenging DS path. Scaling up AFLUX required reconfiguring and increasing resources, which could only be realized by top management. Outspoken management commitment at Mectop seemed to accelerate dedicating resources and managing change, illustrating enhanced strategic agility.

Finally, the comparative case study illustrates the importance of taking an incremental approach, which is aligned with suppliers' and customers' readiness level. Apitec's total solution was too advanced for most of their client's systems. Capabilities held by Ergon were not up to par with customers' needs. Taking smaller steps toward implementing the integral solution might have helped to build momentum and effectively realize it.

\section{Discussion}

Based on the conception of increasing complexity in the content and context of DS and its implementation (Coreynen et al., 2017; Sklyar et al., 2019), a multilevel framework was conceived to facilitate exploring the perpetual DS challenge.

We found that different levels and elements of the multilevel framework were simultaneously involved in the identified critical incidents, confirming the need for a holistic approach to DS. Furthermore, strong interconnectedness between elements within and across levels emerged generating feedback loops between the microfoundational and organizational, organizational and network and the network and microfoundational level (Figure 1). This “domino-effect" seemed to particularly challenge the DS journeys. Managerial 


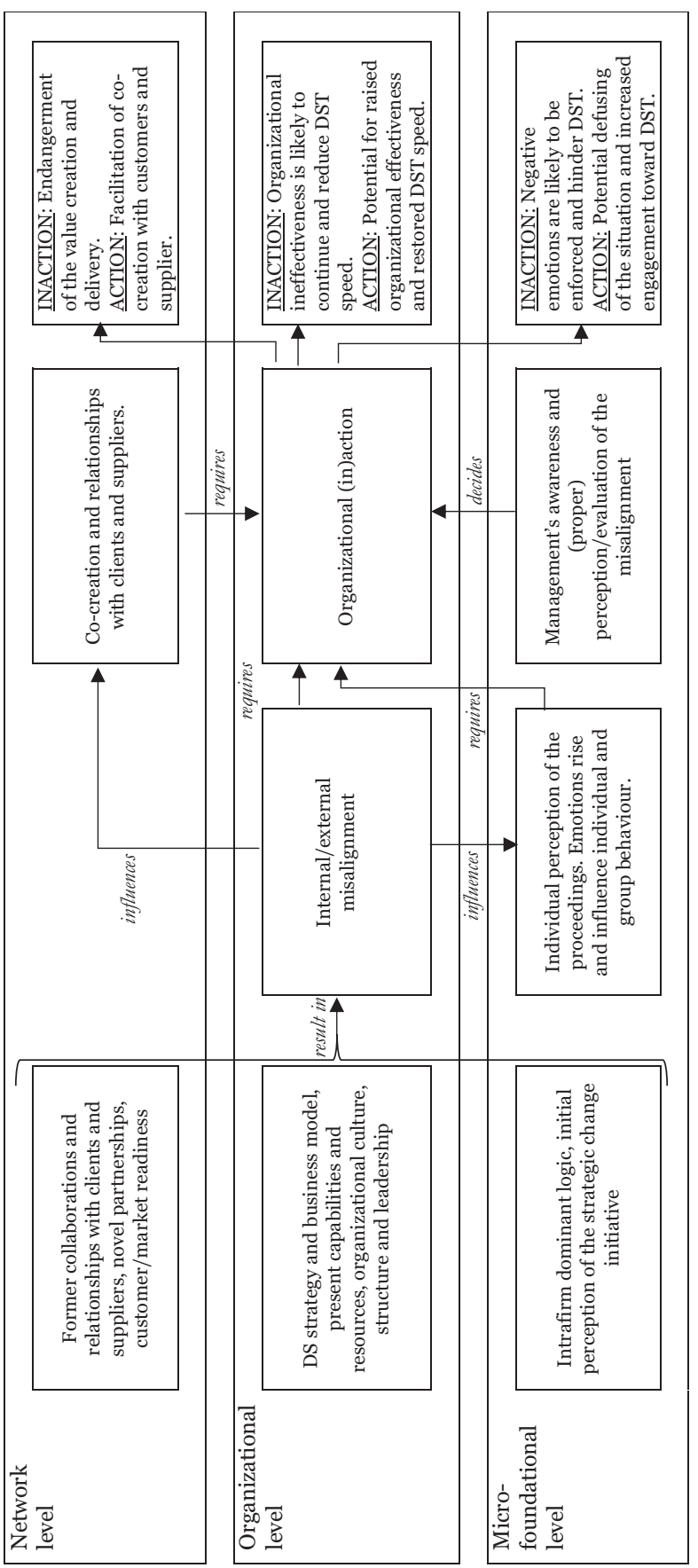

Multilevel perspective on

digital
servitization

digital
servitization 
responses to barriers encountered at one level affected the "health" of other levels. Ineffective organizational responses instigated by improper managerial perception of DS barriers caused multilevel alignment difficulties in consecutive DS stages. Application of the multilevel perspective highlighted the interconnectedness of DS challenges, which seem grafted upon one another, are situated at different levels of analysis and involve a diversity of actors. These interdependencies significantly complicate DS. Hence, we propose DS to be a wicked problem.

Proposition 1. DS implementation is a wicked problem.

Proposition 1a. DS barriers consist of multilevel, multi-actor challenges, which can be hard to discern and of which the definition depends on the observing party.

Proposition 1b. DS barriers are interrelated, interdependent, communicating issues of which the source can be difficult to pinpoint and which have reciprocal implications.

Proposition 1c. No certain, conclusive answers exist to DS barriers since the challenges themselves change with every organizational response made.

By recognizing DS implementation as a wicked problem, we revoke the often-implicit assumptions of DS barriers being independent, clearly discernible and definable issues to which explicit, definite answers exist. Wicked problems are unique, complex problems, which are defined differently by different stakeholders making them particularly intractable. (Cox et al., 2016, p. 3). They are distinguished from familiar challenges to which the solution is well understood. According to Zuiderwijk et al. (2016, p. 223), a wicked problem is characterized by a lack of specific formulation, complex interactions among a variety of stakeholders, a lack of criteria determining a satisfactory solution, including what constitutes "value" and uncertain outcomes.

This description matches the attributes of DS challenges. The successful realization of DS depends on an increasing number of widely varied actors (Sklyar et al., 2019). Each one of them faces different challenges, is privy to only part of the picture and therefore interprets the DS journey differently. For DS to succeed, however, all actors involved must collaborate toward the same end goal. Unfortunately, in DS end goals can often be unclear. Advanced solutions are complex in nature and require co-creation with several value partners (Kohtamäki et al., 2019), making it almost impossible to fully define a solution prior to its development. This, in turn, makes mobilizing partners in the "right direction" extra difficult.

The "wicked" nature of DS, uncovered by the application of the multilevel perspective, might explain why approaches to tackling individual DS barriers have proven insufficient in ensuring smooth transitions. Wicked problems are said to be insolvable by only considering part of the problem (Zuiderwijk et al., 2016, p. 223). We expect a higher-order capability to be essential to managing the interconnectedness within and across multiple levels and stages of the DS journey.

Higher-order capabilities (Collis, 1994) are capabilities that do not affect profit directly but can affect other resources that in turn affect competitive advantage and profit over time. Since profit generation remains a challenge for DS and misalignment has been shown to hamper organizational efficiency (Chorn, 1991) and effectiveness of digital transitions (Yeow et al., 2018), active management of misalignment seems desirable. By productively and proactively managing interdependencies of DS challenges, companies might, for example, more easily overcome the digitization (Kohtamäki et al., 2020) and servitization paradox (Gebauer et al., 2005), resulting in higher DS profits. 
Proposition 2. Effective management of DS challenges consists of an iterative process in which companies shift gears actively, quickly and continuously between observing, analyzing and responding.

Proposition 2a. (Observing): Companies implementing DS require advanced perception and recognition capabilities, which enable them to properly and timely discern DS tensions at network, organizational and microfoundational level.

Proposition 2b. (Analyzing): Companies implementing DS require proactive and continuous (r)evaluation of (potential) DS issues within the multilevel perspective in which they are embedded.

Proposition 2c. (Responding): Companies implementing DS require organizational structures, a flexible mindset and advanced coping strategies, which support agile decision-making and responding to DS challenges present within and between the network, organizational and microfoundational level.

The comparative case study demonstrates the importance of proper discernment of misalignment as a precondition for formulating adequate organizational responses. Actively observing changes in the internal and external environment can facilitate perception. Recognizing the multilevel nature of DS barriers when analyzing challenges - as they occur and proactively - can boost a company's ability to timely develop answers befitting their complexity. As the Mectop case illustrates, having a structure in place for regular (r) evaluation and having access to advanced coping strategies - in this case embodied by Informa - can improve an organization's responding capability. Since companies gain insight into DS barriers by going through the observing, analyzing and responding cycle, we expect that the more companies run through this cycle, the better they will become at coping with DS barriers. Future research can investigate whether companies become more apt at managing the interconnectedness within and across multiple levels as they progress through their DS journey.

Our findings show that an important role is reserved for managers whose responses to the encountered barriers seemed to considerably shape DS outcomes. Certain leadership capabilities such as managerial commitment, strategic agility (Bustinza et al., 2018) and the use of regular measurements to make incremental DS progress visible (Hasselblatt et al., 2018) were found to smoothen the Mectop transition, in line with extant literature. Yeow et al. (2018) already highlighted the distinctly essential role of management for the identification of internal and external tensions and the development of proper organizational responses. Recently, Wibbens (2019, p. 200) found that the quality of managers also contributed to the amount of higher-order capabilities present in the organization, stating that managers can influence the company (and the broader world) beyond mere random variation.

The importance of decisive leadership for DS is expected to rise with the evolving nature of digital solutions, which intensifies technological, organizational and managerial complexity (Paiola and Gebauer, 2020). The more advanced digital solutions become, the more numerous the intrafirm and interfirm interdependencies (Sklyar et al., 2019). In our case, despite limited prior capabilities relating to sales and delivery of services, product-oriented Mectop managed to transition more smoothly than the experienced and service-oriented Apitec. Apitec aimed for a comprehensive solution, which integrated deeply into customers' production processes. Mectop developed a stand-alone solution, which did not enter its clients' systems. Additionally, Mectop managed its DS more proactively.

For managers to effectively reconfigure organizational resources in response to DS barriers, accurate perception of the situation is key (Vanrullen and Thorpe, 2001). 
This necessitates understanding of all the crucial elements involved. The multilevel framework, though inexhaustive, can help raise awareness for "blind spots." Literature states that especially the importance of microlevel processes is often underestimated and insufficiently considered by practitioners and managerial researchers upon the investigation of strategic change (Hodgkinson and Healey, 2014). Our cases confirmed this. With this framework, we aim to inspire future research to increasingly pay attention to microlevel processes on the one hand and the interdependencies across different levels of the multilevel framework on the other.

\section{Conclusion}

The goal of this article was to gain insight into why companies continuously struggle with their DS despite extensive knowledge on hurdles and approaches to overcome them. A multilevel framework was developed to structure the investigation. From its application, a mid-range theory emerged, which challenges the often-implicit assumptions about DS barriers being independent, clearly discernible and definable issues to which explicit, definite answers exist.

Results show that companies implementing DS are faced with a wicked problem consisting of interconnected DS barriers that span across different levels of analysis, that is, the network, organizational and microfoundational level. Responses to misalignment at one level inevitably impact the functioning of other levels, which might lead to the generation of new blockades. Likewise, internal and external misalignments can arise from unawareness of existing tensions and the ensuing unresponsiveness of management. Frictions materialized in frustrations experienced by internal and external stakeholders, organizational inertia and ineffectiveness spill over into the next step of the DS journey. This increases complexity. A higher-order capability of managing the interconnectedness within and between levels and across different steps of DS seems necessary for strategy effectiveness. Rather than treating DS barriers as isolatable challenges and dealing with them in a linear manner, companies would do well to evaluate them iteratively while considering their multilevel nature. By increasingly shifting gears quickly between observing, analyzing and responding, companies may smoothen their DS. Researchers are invited to test the developed midrange theory and propositions to generate increased understanding of its applicability in different settings and further unravel DS complexity.

With this study, several theoretical contributions were made. First, we answer the call from Rabetino et al. (2018) for mid-range theories that address the organizational change aspect of servitization. Second, by recognizing DS as a wicked problem, we open a new avenue for future research in which the interconnectedness between and within DS barriers is explicitly recognized. Researchers are encouraged to further investigate what and who could contribute to shaping the proposed higher-order capability. Additional inspiration regarding coping strategies may be found in wicked problem literature. Third, our study fits the DS research agenda drawn up by Paschou et al. (2020, p. 288), who pointed out the need for a more systemic and holistic approach to DS and models and frameworks that support decisionmaking. We developed and empirically tested a comprehensive multilevel framework, which extends beyond the evaluation of traditional dyadic relationships and can be applied by DS practitioners and researchers alike. Finally, our comparative case study provides empirical data on the essential role affective processes play in strategy development and execution. By illustrating the impact perceptions and emotions have on strategic change, we aim to inspire continuing research into this underdeveloped area (Hodgkinson and Healey, 2014).

Benefits are also available to DS practitioners wishing to use the multilevel framework. First, the framework can boost practitioner's awareness of the multilevel nature of their DS and its building blocks requiring attention. This might encourage continuous monitoring of 
essential elements, which in turn facilitates timely and proper managerial perception of DS barriers. Secondly, the framework supports the proactive development of potential organizational responses and their multilevel impact evaluation. Finally, by deconstructing complexity of the DS journey and presenting the challenge in a neutral, overarching frame, the model might enhance communication among DS's diverse partners, accelerating the realization of a shared understanding and interfirm alignment. Hence, we believe the framework might be a first step to supporting manufacturers in the development of their higher-order capability for managing multilevel DS interdependencies.

Despite significant contributions made, our research has its limitations. Data was gathered at the individual level in a mainly retrospective manner. This implies a risk for bias through misremembrance of facts and selective forgetting (Lind et al., 2017). To counter this, we took a multi-actor approach and verified insights in consecutive interviews. Nevertheless, future research could benefit from a mixed methods approach (Molina-Azorín et al., 2020). Additionally, researchers are encouraged to apply the multilevel framework to several settings in which both the context (environment) and the content (DS strategy) differ. This could help to validate our insights and uncover additional DS complexity. For example, in the Mectop case, Italy's national policy was found to have a strong positive impact on customer's willingness to embark on digitization. This facilitated Mectop's DS. Belgian customers, however, did not benefit from financial incentives aimed at Industry 4.0 projects. Though we assume that the role of (supra)national financial injections can smoothen DS strategies, no certain claims can be made based on this limited contextual data. Future research might investigate the role (supra)national initiatives play in the success of DS strategies. Finally, given leadership's important role for DS, research that dives deeper into leadership styles, characteristics and attributes that underwrite commitment and consonance among managers could be beneficial to furthering the field.

\section{Notes}

1. Information structures and mental maps. Gary, M.S. and Wood, R.E. (2011), "Mental models, decision rules, and performance heterogeneity", Strategic management journal, Vol. 32, pp. 569-594.

2. To ensure confidentiality, the names of both companies, their partners as well as specific technologies and software programs have been changed. Some numbers and dates were altered for privacy reasons. Alterations in the display of the data, however, did not affect the interpretation of the data.

\section{References}

Adner, R. (2017), "Ecosystem as structure: an actionable construct for strategy", Journal of Management, Vol. 43, pp. 39-58, doi: 10.1177/0149206316678451.

Alghisi, A. and Saccani, N. (2015), "Internal and external alignment in the servitization journey -overcoming the challenges", Production Planning and Control, Vol. 26, pp. 1219-1232, doi: 10. 1080/09537287.2015.1033496.

Alvesson, M. and Sandberg, J. (2013), "Has management studies lost its way? Ideas for more imaginative and innovative research", Journal of Management Studies, Vol. 50, pp. 128-152, doi: 10.1111/j.1467-6486.2012.01070.

Ashkanasy, N.M., Humphrey, R.H. and Huy, Q.N. (2017), "Integrating emotions and affect in theories of management”, Academy of Management Review, Vol. 42, pp. 175-189, doi: 10.5465/amr. 2016.0474.

Barsade, S.G. (2002), "The ripple effect: emotional contagion and its influence on group behavior", Administrative Science Quarterly, Vol. 47, pp. 644-675, doi: 10.2307/3094912.

Bott, G. and Tourish, D. (2016), "The critical incident technique reappraised", Qualitative Research in Organizations and Management, Vol. 11 No. 4, pp. 276-300, doi: 10.1108/QROM-01-2016-1351. 
Bustinza, O.F., Gomes, E., Vendrell-Herrero, F. and Tarba, S.Y. (2018), "An organizational change framework for digital servitization: evidence from the Veneto region”, Strategic Change, Vol. 27 No. 2, pp. 111-119, doi: 10.1002/jsc.2186.

Cenamor, J., Sjödin, D.R. and Parida, V. (2017), "Adopting a platform approach in servitization: leveraging the value of digitalization”, International Journal of Production Economics, Vol. 192, pp. 54-65, doi: 10.1016/j.ijpe.2016.12.033.

Chorn, N.H. (1991), “The 'alignment' theory: creating strategic fit”, Management Decision, Vol. 29 No. 1, doi: 10.1108/EUM0000000000066.

Collis, D.J. (1994), "Research note: how valuable are organizational capabilities?", Strategic Management Journal, Vol. 15 No. S1, pp. 143-152, doi: 10.1002/smj.4250150910.

Coreynen, W., Matthyssens, P. and Van Bockhaven, W. (2017), "Boosting servitization through digitization: pathways and dynamic resource configurations for manufacturers", Industrial Marketing Management, Vol. 60, pp. 42-53, doi: 10.1016/j.indmarman.2016.04.012.

Coreynen, W., Vanderstraeten, J., van Witteloostuijn, A., Cannaerts, N., Loots, E. and Slabbinck, H. (2020), "What drives product-service integration? An abductive study of decision-makers' motives and value strategies", Journal of Business Research, Vol. 117, pp. 189-200, doi: 10.1016/j. jbusres.2020.05.058.

Cox, A.M., Pinfield, S. and Smith, J. (2016), "Moving a brick building: UK libraries coping with research data management as a 'wicked' problem", Journal of Librarianship and Information Science, Vol. 48 No. 1, pp. 3-17, doi: 10.1177/0961000614533717.

Dubois, A. and Gadde, L.E. (2002), "Systematic combining: an abductive approach to case research", Journal of Business Research, Vol. 55, pp. 553-560, doi: 10.1016/S0148-2963(00) 00195-8.

Durand, M. (2016), "Employing critical incident technique as one way to display the hidden aspects of post-merger integration”, International Business Review, Vol. 25 No. 1, pp. 87-102, doi: 10.1016/j. ibusrev.2015.05.003.

Eisenhardt, K.M. (1989), "Building theories from case study research", Academy of Management Review, Vol. 14, pp. 532-550, doi: 10.5465/amr.1989.4308385.

Felin, T., Foss, N.J. and Ployhart, R.E. (2015), "The microfoundations movement in strategy and organization theory", Academy of Management Annals, Vol. 9, pp. 575-632, doi: 10.5465/ 19416520.2015.1007651.

Flanagan, J.C. (1954), “The critical incident technique”, Psychological Bulletin, Vol. 51 No. 4, pp. 327-358, doi: $10.1037 / \mathrm{h} 0061470$.

Frank, A.G., Dalenogare, L.S. and Ayala, N.F. (2019), "Industry 4.0 technologies: implementation patterns in manufacturing companies", International Journal of Production Economics, Vol. 210, pp. 15-26, doi: 10.1016/j.ijpe.2019.01.004.

Gebauer, H., Fleisch, E. and Friedli, T. (2005), "Overcoming the service paradox in manufacturing companies", European Management Journal, Vol. 23 No. 1, pp. 14-26, doi: 10.1016/j.emj.2004. 12.006 .

Gebauer, H., Arzt, A., Kohtamäki, M., Lamprecht, C., Parida, V., Witell, L. and Wortmann, F. (2020a), "How to convert digital offerings into revenue enhancement - conceptualizing business model dynamics through explorative case studies", Industrial Marketing Management, Vol. 91, pp. 429-441, doi: 10.1016/j.indmarman.2020.10.006.

Gebauer, H., Fleisch, E., Lamprecht, C. and Wortmann, F. (2020b), "Growth paths for overcoming the digitalization paradox", Business Horizons, Vol. 63 No. 3, pp. 313-323, doi: 10.1016/j.bushor.2020. 01.005 .

Gioia, D.A. and Chittipeddi, K. (1991), "Sensemaking and sensegiving in strategic change initiation”, Strategic Management Journal, Vol. 12, pp. 433-448, doi: 10.1002/smj. 4250120604 . 
Grandinetti, R., Ciasullo, M.V., Paiola, M. and Schiavone, F. (2020), "Fourth industrial revolution, digital servitization and relationship quality in Italian $\mathrm{B} 2 \mathrm{~B}$ manufacturing firms. An exploratory study”, The TQM Journal, Vol. 32 No. 4, pp. 647-671, doi: 10.1108/TQM-01-2020-0006.

Hämäläinen, H. (2020), "The effect of digital servitization to the boundaries of firms", available at: http://urn.fi/URN:NBN:fi:aalto-202005243260 (accessed 22 July 2020).

Hasselblatt, M., Huikkola, T., Kohtamäki, M. and Nickell, D. (2018), "Modeling manufacturer's capabilities for the internet of things", Journal of Business and Industrial Marketing, Vol. 33 No. 6, pp. 822-836, doi: 10.1108/JBIM-11-2015-0225.

Healey, M.P. and Hodgkinson, G.P. (2017), "Making strategy hot", California Management Review, Vol. 59, pp. 109-134, doi: 10.1177/0008125617712258.

Helfat, C.E. and Peteraf, M.A. (2015), "Managerial cognitive capabilities and the microfoundations of dynamic capabilities", Strategic Management Journal, Vol. 36, pp. 831-850, doi: 10.1002/ smj.2247.

Helfat, C.E. and Raubitschek, R.S. (2018), "Dynamic and integrative capabilities for profiting from innovation in digital platform-based ecosystems", Research Policy, Vol. 47 No. 8, pp. 1391-1399, doi: 10.1016/.j.respol.2018.01.019.

Hitt, M.A., Beamish, P.W., Jackson, S.E. and Mathieu, J.E. (2007), "Building theoretical and empirical bridges across levels: multilevel research in management", Academy of Management Journal, Vol. 50, pp. 1385-1399, doi: 10.5465/amj.2007.28166219.

Hodgkinson, G.P. and Healey, M.P. (2014), "Coming in from the cold: the psychological foundations of radical innovation revisited”, Industrial Marketing Management, Vol. 43, pp. 1306-1313, doi: 10. 1016/j.indmarman.2014.08.012.

Kamalaldin, A., Linde, L., Sjödin, D. and Parida, V. (2020), "Transforming provider-customer relationships in digital servitization: a relational view on digitalization", Industrial Marketing Management, Vol. 89, pp. 306-325, doi: 10.1016/j.indmarman.2020.02.004.

Klein, K.J., Tosi, H. and Cannella, A.A. Jr (1999), "Multilevel theory building: benefits, barriers, and new developments", Academy of Management Review, Vol. 24, pp. 248-253, doi: 10.5465/amr. 1999.1893934.

Kohtamäki, M., Parida, V., Oghazi, P., Gebauer, H. and Baines, T. (2019), "Digital servitization business models in ecosystems: a theory of the firm”, Journal of Business Research, Vol. 104, pp. 380-392, doi: 10.1016/j.jbusres.2019.06.027.

Kohtamäki, M., Parida, V., Patel, P.C. and Gebauer, H. (2020), "The relationship between digitalization and servitization: the role of servitization in capturing the financial potential of digitalization", Technological Forecasting and Social Change, Vol. 151, pp. 1-9, doi: 10.1016/j.techfore.2019. 119804.

Kowalkowski, C., Gebauer, H. and Oliva, R. (2017), "Service growth in product firms: past, present, and future”, Industrial Marketing Management, Vol. 60, pp. 82-88, doi: 10.1016/j.indmarman.2016. 10.015 .

Lenka, S. (2018), "Managing the transformation towards advanced service provision: a multilevel framework of servitization", available at: https://www.diva-portal.org/smash/record.jsf? pid $=$ diva2\%3A1163149\&dswid $=7927$ (accessed 13 August 2020).

Lenka, S., Parida, V., Sjödin, D.R. and Wincent, J. (2018a), "Exploring the microfoundations of servitization: how individual actions overcome organizational resistance", Journal of Business Research, Vol. 88, pp. 328-336, doi: 10.1016/j.jbusres.2017.11.021.

Lenka, S., Parida, V., Sjödin, D.R. and Wincent, J. (2018b), "Towards a multi-level servitization framework. Conceptualizing ambivalence in manufacturing firms", International Journal of Operations and Production Management, Vol. 38 No. 3, pp. 810-827, doi: 10.1108/IJOPM-092016-0542.

Lind, M., Visentini, M., Mäntylä, T. and Del Missier, F. (2017), "Choice-supportive misremembering: a new taxonomy and review”, Frontiers in Psychology, Vol. 8, pp. 1-16, doi: 10.3389/fpsyg.2017.02062. 
Lusch, R.F. and Vargo, S.L. (2014), Service-dominant Logic: Premises, Perspectives, Possibilities, Cambridge University Press, Cambridge.

Matthyssens, P. and Vandenbempt, K. (2003), "Cognition-in-context: reorienting research in business market strategy", Journal of Business and Industrial Marketing, Vol. 18 Nos 6/7, pp. 595-606, doi: $10.1108 / 08858620310492446$.

Matthyssens, P. and Vandenbempt, K. (2008), "Moving from basic offerings to value-added solutions: strategies, barriers and alignment”, Industrial Marketing Management, Vol. 37, pp. 316-328, doi: 10.1016/j.indmarman.2007.07.008.

Molina-Azorín, J.F., Pereira-Moliner, J., López-Gamero, M.D., Pertusa-Ortega, E.M. and Tarí, J.J. (2020), "Multilevel research: foundations and opportunities in management", BRQ Business Research Quarterly, Vol. 23 No. 4, pp. 319-333, doi: 10.1016/j.brq.2019.03.004.

Paiola, M. and Gebauer, H. (2020), "Internet of things technologies, digital servitization and business model innovation in BtoB manufacturing firms", Industrial Marketing Management, Vol. 89, pp. 245-264, doi: 10.1016/j.indmarman.2020.03.009.

Parida, V., Sjödin, D. and Reim, W. (2019), "Reviewing literature on digitalization, business model innovation, and sustainable industry: past achievements and future promises", Sustainability, Vol. 11 No. 2, pp. 391-408, doi: 10.3390/su11020391.

Partington, D. (2000), "Building grounded theories of management action", British Journal of Management, Vol. 11, pp. 91-102, doi: 10.1111/1467-8551.00153.

Paruchuri, S., Perry-Smith, J.E., Chattopadhyay, P. and Shaw, J.D. (2018), "New ways of seeing: pitfalls and opportunities in multilevel research", Academy of Management Journal, Vol. 61 No. 3, pp. 797-801, doi: 10.5465/amj.2018.4003.

Paschou, T., Rapaccini, M., Adrodegari, F. and Saccani, N. (2020), "Digital servitization in manufacturing: a systematic literature review and research agenda", Industrial Marketing Management, Vol. 89, pp. 278-292, doi: 10.1016/j.indmarman.2020.02.012.

Patton, M.Q. (2005), "Qualitative research", in Everitt, B.S. and Howell, H. (Eds), Encyclopedia of Statistics in Behavioral Science, Wiley, New Jersey, NJ, doi: 10.1002/0470013192.bsa514.

Pettigrew, A.M. (1992), "The character and significance of strategy process research", Strategic Management Journal, Vol. 13, pp. 5-16, doi: 10.1002/smj.4250130903.

Pratt, M.G. (2009), "From the editors: for the lack of a boilerplate: tips on writing up (and reviewing) qualitative research", Academy of Management Journal, Vol. 52 No. 5, pp. 856-862, doi: 10.5465/ amj.2009.44632557.

Quintens, L. and Matthyssens, P. (2010), "Involving the process dimensions of time in case-based research”, Industrial Marketing Management, Vol. 39 No. 1, pp. 91-99, doi: 10.1016/j.indmarman. 2008.04.018.

Rabetino, R., Kohtamäki, M. and Gebauer, H. (2017), "Strategy map of servitization”, International Journal of Production Economics, Vol. 192, pp. 144-156, doi: 10.1016/j.ijpe.2016.11.004.

Rabetino, R., Harmsen, W., Kohtamäki, M. and Sihvonen, J. (2018), "Structuring servitization-related research", International Journal of Operations and Production Management, Vol. 38 No. 2, pp. 350-371, doi: 10.1108/IJOPM-03-2017-0175.

Raddats, C., Zolkiewski, J., Story, V.M., Burton, J., Baines, T. and Ziaee Bigdeli, A. (2017), "Interactively developed capabilities: evidence from dyadic servitization relationships", International Journal of Operations and Production Management, Vol. 37 No. 3, pp. 382-400, doi: 10.1108/IJOPM-082015-0512.

Raddats, C., Kowalkowski, C., Benedettini, O., Burton, J. and Gebauer, H. (2019a), "Servitization: a contemporary thematic review of four major research streams", Industrial Marketing Management, Vol. 83, pp. 207-223, doi: 10.1016/j.indmarman.2019.03.015.

Raddats, C., Story, V., Burton, J. and Zolkiewski, J. (2019b), "Digital capabilities for advanced services: a multi-actor perspective", Proceedings of the Spring Servitization Conference 2019, Linköping, pp. 21-27. 
Raffaelli, R., Glynn, M.A. and Tushman, M. (2019), "Frame flexibility: the role of cognitive and emotional framing in innovation adoption by incumbent firms", Strategic Management Journal, Vol. 40, pp. 1013-1039, doi: 10.1002/smj.3011.

Rapaccini, M., Saccani, N., Kowalkowski, C., Paiola, M. and Adrodegari, F. (2020), "Navigating disruptive crises through service-led growth: the impact of COVID-19 on Italian manufacturing firms”, Industrial Marketing Management, Vol. 88, pp. 225-237, doi: 10.1016/j.indmarman.2020. 05.017.

Saunila, M., Ukko, J. and Rantala, T. (2019), "Value co-creation through digital service capabilities: the role of human factors", Information Technology and People, Vol. 32 No. 3, pp. 627-645, doi: 10. 1108/ITP-10-2016-0224.

Scott, W.R. (1992), Organizations: Rational, Natural, and Open Systems, Prentice hall, New Jersey, NJ.

Siggelkow, N. (2007), "Persuasion with case studies", Academy of Management Journal, Vol. 50, pp. 20-24, doi: 10.5465/amj.2007.24160882.

Silverman, D. (2008), Qualitative Research: Theory, Method, and Practice, Sage Publications, London.

Sjödin, D.R., Parida, V., Kohtamäki, M. and Wincent, J. (2020), "An agile co-creation process for digital servitization: a micro-service innovation approach”, Journal of Business Research, Vol. 112, pp. 478-491, doi: 10.1016/j.jbusres.2020.01.009.

Sklyar, A., Kowalkowski, C., Tronvoll, B. and Sörhammar, D. (2019), "Organizing for digital servitization: a service ecosystem perspective", Journal of Business Research, Vol. 104, pp. 450-460, doi: 10.1016/j.jbusres.2019.02.012.

Story, V.M., Raddats, C., Burton, J., Zolkiewski, J. and Baines, T. (2017), “Capabilities for advanced services: a multi-actor perspective”, Industrial Marketing Management, Vol. 60, pp. 54-68, doi: 10.1016/j.indmarman.2016.04.015.

Tronvoll, B., Sklyar, A., Sörhammar, D. and Kowalkowski, C. (2020), “Transformational shifts through digital servitization”, Industrial Marketing Management, Vol. 89, pp. 293-305, doi: 10.1016/j. indmarman.2020.02.005.

Vaittinen, E. and Martinsuo, M. (2019), “Industrial customers' organizational readiness for new advanced services", Journal of Manufacturing Technology Management, Vol. 30 No. 7, pp. 1073-1096, doi: 10.1108/JMTM-07-2018-0194.

Vandermerwe, S. and Rada, J. (1988), "Servitization of business: adding value by adding services", European Management Journal, Vol. 6 No. 4, pp. 314-324, doi: 10.1016/0263-2373(88)90033-3.

Vanrullen, R. and Thorpe, S.J. (2001), "The time course of visual processing: from early perception to decision-making", Journal of Cognitive Neuroscience, Vol. 13, pp. 454-461, doi: 10.1162/ 08989290152001880 .

Vendrell-Herrero, F., Bustinza, O., Parry, G. and Georgantzis, N. (2017), "Servitization, digitization and supply chain interdependency", Industrial Marketing Management, Vol. 60, pp. 69-81, doi: 10. 1016/j.indmarman.2016.06.013.

Vuori, T.O. and Huy, Q.N. (2016), "Distributed attention and shared emotions in the innovation process: how Nokia lost the smartphone battle", Administrative Science Quarterly, Vol. 61, pp. 9-51, doi: 10.1177/0001839215606951.

Waldman, D.A., Wang, D. and Fenters, V. (2019), "The added value of neuroscience methods in organizational research”, Organizational Research Methods, Vol. 22, pp. 223-249, doi: 10.1177/ 1094428116642013.

Wibbens, P.D. (2019), "Performance persistence in the presence of higher-order resources", Strategic Management Journal, Vol. 40 No. 2, pp. 181-202, doi: 10.1002/smj.2979.

Yeow, A., Soh, C. and Hansen, R. (2018), "Aligning with new digital strategy: a dynamic capabilities approach”, The Journal of Strategic Information Systems, Vol. 27, pp. 43-58, doi: 10.1016/j.jsis. 2017.09.001.

Yin, R.K. (2011), Applications of Case Study Research, Sage Publications, California, CA. 
Zhang, W. and Banerji, S. (2017), "Challenges of servitization: a systematic literature review", Industrial Marketing Management, Vol. 65, pp. 217-227, doi: 10.1016/j.indmarman.2017.06.003.

Zuiderwijk, A., Janssen, M., Van de Kaa, G. and Poulis, K. (2016), "The wicked problem of commercial value creation in open data ecosystems: policy guidelines for governments", Information Polity, Vol. 21 No. 3, pp. 223-236, doi: 10.3233/IP-160391.

\section{Corresponding author}

Serena Galvani can be contacted at: s.galvani2@campus.uniurb.it

For instructions on how to order reprints of this article, please visit our website: www.emeraldgrouppublishing.com/licensing/reprints.htm Or contact us for further details: permissions@emeraldinsight.com 